\title{
Diálogos sobre formação docente comprometida com uma escola pública popular ${ }^{1}$
}

\section{Dialogues on teacher education committed to a popular public school}

\section{Diálogos sobre formación del profesorado comprometida con una escuela pública popular}

\author{
Maria Teresa Esteban² \\ DOI: http://dx.doi.org/10.20435/serie-estudos.v20i52.1355
}

\begin{abstract}
Resumo: O artigo aborda articulações entre formação docente e educação das classes populares, focalizando relações entre escola básica e universidade. Tem como principais referências os trabalhos de Paulo Freire e de Regina Leite Garcia, que oferecem as bases para a construção de uma escola pública popular e convocam a pensar em pedagogias emancipatórias. Fundadas no diálogo, tais pedagogias convidam ao trabalho coletivo, reflexivo, crítico, comprometido e esperançoso. Uma perspectiva em que os vínculos entre o fazer docente e a pesquisa se estreitam, conforme indica a conclusão do trabalho ao assinalar a potência dos princípios da Educação Popular e a relevância da noção de professora pesquisadora para a problematização de questões escolares cotidianas e a busca de alternativas para sua transformação.
\end{abstract}

Palavras-chave: formação docente; Educação Popular; escola pública; professora pesquisadora.

Abstract: The article addresses articulations between teacher education and popular classes education, focusing on relations between elementary school and university. Its main references are the works of Paulo Freire and Regina Leite Garcia, which provide the basis for the construction of a popular public school and call for thinking in emancipatory pedagogies. Founded in dialogue, these pedagogies invite collective, reflective, critical, committed and hopeful work. A perspective in which the links between teaching and research are tightened, as indicated by the conclusion of the work by pointing out the power of the principles of Popular Education and the relevance of the notion of researcher teacher for the problem-posing of everyday school issues and the search for alternatives for its transformation.

Keywords: teacher education; Popular Education; public school; researcher teacher.

Resumen: El artículo aborda articulaciones entre formación del profesorado y educación de las clases populares, con el foco en las relaciones entre educación básica y universidad. Sus principales

\footnotetext{
1 Trabalho realizado a partir de pesquisa financiada pela FAPERJ e pelo CNPq.

2 Universidade Federal Fluminense (UFF), Niterói, Rio de Janeiro, Brasil.
} 
referencias son los trabajos de Paulo Freire y Regina Leite Garcia, que ofrecen las bases para la construcción de una escuela pública popular y convocan a pensar en pedagogías emancipatorias. Fundadas en el diálogo, tales pedagogías invitan al trabajo colectivo, reflexivo, crítico, comprometido y con esperanza. Una perspectiva en que los lazos entre el hacer docente y la investigación se fortalecen, conforme indica la conclusión del trabajo cuando señala la potencia de los principios de la Educación Popular y de la noción de profesora investigadora para la problematización de cuestiones escolares cotidianas y la búsqueda de alternativas para su transformación.

Palabras clave: formación del profesorado; Educación Popular; escuela pública; profesora investigadora.

Pensar que a esperança sozinha transforma o mundo e atuar movido por tal ingenuidade é um modo excelente de tombar na desesperança, no pessimismo, no fatalismo. Mas prescindir da esperança na luta para melhorar o mundo, como se a luta se pudesse reduzir a atos calculados apenas, à pura cientificidade, é frívola ilusão. (Paulo Freire)

\section{INTRODUÇÃO}

As professoras têm ocupado um importante lugar na conexão entre as classes populares e a escola pública brasileira. Diariamente, as professoras vivem desafios, tensões e possibilidades que se produzem no encontro, instigante embora nem sempre harmônico, entre os múltiplos saberes que transitam em suas salas de aula, trazidos pelos diferentes sujeitos que constituem a vida escolar.

Nesse cotidiano intenso e plural se encontram crianças, adolescentes, jovens e adultos dos segmentos sociais oprimidos, subalternizados, que temos denominado como classes populares. Sua presença na escola se expandiu significativamente nas últimas décadas, sendo acompanhada de modo crescente pela ampliação de seu percurso de escolarização. Em período mais recente, vem aumentando bastante o número de estudantes das classes populares nas universidades, o que imprime novos contornos aos cursos de Pedagogia ${ }^{3}$ e apresenta novas questões aos processos de formação docente (ESTEBAN; ECKHARDT, 2019). Essa nova feição que a educação vai assumindo expressa conquistas de sujeitos historicamente em luta contra a exclusão do direito à escola como parte de um conjunto mais am-

3 Tal processo é extensivo às demais licenciaturas, porém, neste artigo, trato exclusivamente do curso de Pedagogia. 
plo de direitos que lhes são negados (ARROYO, 2011). Esse movimento também incide na definição de qualidade da educação e em muitas das ações no sentido de aprofundar a qualidade da escola pública. Certamente, é uma questão para a qual as respostas já dadas, mesmo relevantes, ainda se mostram insuficientes.

No cotidiano da escola e da universidade, encontramos indicadores da necessária conexão entre a Educação Pública e a Educação Popular, especialmente quando queremos dar consequência ao compromisso com uma educação e, portanto, com uma escolarização de "qualidade democrática, científica e pedagógica" (AFONSO, 1999). Esta opção requer estar com as classes populares, dialogar com elas e tê-las como parceiras na tecelagem dos processos educacionais. Nesse sentido, não podemos abrir mão da longa experiência e consistente produção da Educação Popular.

A qualidade da escola pública brasileira tem relação com a possibilidade de constituir-se como um espaço no qual se mobilizam experiências dialógicas e de revitalizar-se como tempo de movimentos coletivos fomentados pelo ser mais (FREIRE, 2006). O entendimento da articulação entre formação docente e educação das classes populares - tanto por se direcionar a uma escola em que as classes populares se encontram massivamente quanto por serem de classes populares muitos/as dos/as estudantes dos cursos de Pedagogia - lança muitas possibilidades para pensarmos o processo formativo, sempre entretecidas em muitos desafios.

Com essa compreensão, tomo como central neste artigo a relação entre a escola básica e a universidade a partir de desafios postos pelo cotidiano à formação docente. Esta abordagem sintoniza com movimentos demarcados pela pesquisa em formação de professores, conforme se pode depreender de estudo realizado por Romanowski (2012) sobre a produção acadêmica nesse campo. Segundo a autora, o I Simpósio de Grupos de Pesquisas sobre Formação de Professores ${ }^{4}$ indicou a formação de professores/as para a educação básica, a parceria entre pesquisadores/as e professores/as na busca de soluções dos problemas da escola e a formação do/a professor/a-pesquisador/a como algumas das prioridades para a investigação, resultado convergente para o encontrado por Brzezinski ao

4 Evento realizado pelo GT Formação de Professores da Anped, na PUC/SP, em 2006, com a participação de pesquisadores, representantes de grupos de pesquisa. 
analisar amostra das dissertações e teses sobre a formação dos/as profissionais da educação, tanto no período de 1997 a 2002, citado no referido estudo de Romanowski, quanto em pesquisa realizada sobre período posterior - 2008 a 2010 - (BRZEZINSKI; 2014). Em ambos, a autora observa a presença de temas como práticas pedagógicas reflexivas, suas relações com processos formativos e a escola como espaço de formação, em elevado número de estudos.

O reconhecimento do potencial formativo das experiências escolares ressalta a complexidade dos processos de formação e chama a atenção aos riscos de sua simplificação. O trabalho com o cotidiano escolar exige cautela. Preciso, portanto, estar atenta aos movimentos e, sabendo da existência de riscos, nem sempre previsíveis e tantas vezes inevitáveis, exercitar a escuta respeitosa, o olhar minucioso, o toque delicado, o silêncio prudente, a fala responsável e a escrita reflexiva, para viver o encontro e torná-lo tempo de problematização e de aprendizagem. Pretendo este artigo como expressão destes gestos, mobilizada por questões que emergem da reflexão sobre as práticas escolares cotidianas, em diálogo com as professoras, no âmbito da pesquisa.

Minha proposta se conduz no diálogo com Paulo Freire ${ }^{5}$ e Regina Leite Garcia, cujos trabalhos tanto oferecem para a atuação na formação e na pesquisa comprometidas com a escola pública popular. Esta escolha se ampara na convocação dos autores para se pensar as pedagogias como processos que ganham significações quando se produzem como relações dialógicas; convite ao trabalho coletivo, reflexivo, crítico, comprometido e esperançoso.

Essas abordagens constituem referentes para a pesquisa que coordeno ${ }^{6}$, com docentes de escolas públicas, atuando fundamentalmente com crianças das classes populares. Nesse trabalho, voltado à reflexão sobre a dinâmica pedagógica no processo de alfabetização no novo contexto institucional que se constitui com a consolidação da avaliação externa em larga escala, produzem-se as questões com que alinhavo este artigo. É uma pesquisa qualitativa, que identificamos como estudo com o cotidiano (GARCIA, 2003a), conforme será tratado ao longo deste texto.

5 O estudo de Brzezinski (2014) evidencia Paulo Freire como o autor mais consultado, entre os nacionais e estrangeiros, pelos/as autores/as das dissertações e teses incluídas em sua pesquisa.

6 A pesquisa envolve seis escolas (em quatro municípios), sete turmas, dez professoras, aproximadamente cem crianças, além de seis componentes do grupo de pesquisa. 
Os nossos encontros com as professoras e o acompanhamento de seu trabalho nos indicaram diversas questões relevantes, dentre elas, fragilidades na compreensão das relações entre a escola pública e as classes populares, bem como a potência da reflexão coletiva sobre a dimensão popular desta escola em que nosso trabalho se efetiva. Nessa reflexão, emerge também a formação da professora pesquisadora, articulada ao aprofundamento do estudo sobre o processo de formação docente, diante dos desafios postos pelas novas conformações que a escola vem assumindo.

\section{A ESCOLA PÚBLICA POPULAR COMO DESAFIO À (FORM)AÇÃO DOCENTE}

Paulo Freire nos dá mais do que régua e compasso para fazermos do trabalho pedagógico espaçotempo de encontro com o outro, tornando possível a partilha de conhecimentos e a produção de percursos para sua produção/apropriação/ socialização/problematização. Freire nos oferece fios, cores, sabores, cheiros e afetos com os quais tecemos conhecimentos e com eles nos entretecemos, enquanto nos entrelaçamos ao mundo, na vida, tendo como horizonte a escola pública popular.

A obra de Freire formula uma epistemologia crítica, em que a construção do mundo se dá fundamentalmente como processo de conhecimento e a constituição do sujeito se entretece na sua atividade, sendo o outro condição de sua existência (BECKER, 2010). A epistemologia freireana se volta à vida prática e trata a experiência dialógica no processo de construção de conhecimento como uma exigência radical, questionando, assim, o dualismo sujeito-objeto. Afirma o estatuto epistêmico dos sujeitos das classes populares ao tomar como central, no processo de conhecer, a realidade material e simbólica destes que são historicamente destituídos de seu lugar de saber na ordem social dominante (PEREIRA, 2014). Propõe o conhecimento como processo dialógico, intersubjetivo e dialético; ato ético em que a autonomia se exerce na relação com a liberdade, sempre articulada à solidariedade, como parte de um projeto de transformação social.

A epistemologia freireana se realiza numa pedagogia cuja intenção é "formar pensamentos e subjetividades emancipadoras" (TORRES, 2013, p. 27). Vinculada aos sujeitos subalternizados, traduz-se em propostas e reflexões constitutivas dos fundamentos da Educação Popular, como movimento latino- 
-americano. A Educação Popular, parte do projeto de emancipação, tem no conhecimento o núcleo dessa educação libertadora, indispensável à composição da escola pública. A escola pública popular, ainda um projeto fragilmente delineado nas ações cotidianas, constitui-se pela recriação e contextualização da pedagogia do oprimido, por ser uma "pedagogia dos seres humanos [homens ${ }^{7}$ ] empenhando-se na luta por sua libertação" (FREIRE, 2006, p. 45). Pensada na interação entre educação e cultura popular, propõe-se como prática de liberdade e anuncia uma escola em que conhecimento e liberdade se conjugam para potencializar o reconhecimento dos saberes populares, a apropriação dos conhecimentos científicos e a organização política das classes populares. Atos amorosos, necessários ao movimento humanizador que fomenta a elaboração de propostas contra-hegemônicas.

Streck (2010) afirma a obra freireana como um momento de ruptura no qual há libertação da própria pedagogia do modelo forjado na modernidade, pois, ao formulá-la como do oprimido, instaura-a como uma pedagogia do outro. Nos argumentos que dão sustentação a essa compreensão, o autor ressalta dois deslocamentos relevantes: o primeiro, da educação do indivíduo para ser o cidadão para a educação de uma classe social, que toma para si o ensinar e o aprender como necessários ao seu posicionamento como sujeito (coletivo) do conhecimento; o segundo, de uma prática tecnicista para o compromisso com a práxis transformadora.

Nesse duplo deslocamento, o diálogo se evidencia como condição indispensável para uma pedagogia libertadora, por ser um ato de liberdade que gera outros atos de liberdade. Para Freire (2006, p. 91), "o diálogo é este encontro dos seres humanos [homens], mediatizados pelo mundo, para pronunciá-lo, não se esgotando, portanto, na relação eu-tu". Assim, afirma-se como ato amoroso, comprometido, conectado à problematização e resposta ao desafio de que os encontros sejam tempo de se falar com o outro, e não de se falar para o outro. O diálogo possibilita um debruçar-se sobre o mundo como humanamente produzido e viver o inacabamento como condição da existência humana, que mobiliza constantemente a ir além dos limites encontrados. O diálogo viabiliza a

\footnotetext{
7 No texto, Freire escreve homens. Faço a substituição considerando sua observação na Pedagogia da Esperança em relação a sua escrita machista em Pedagogia do Oprimido.
} 
crítica, a compreensão de que o mundo não é, mas está sendo, e o vislumbre do ser mais; demanda confiança, promove solidariedade e fortalece a esperança, o que cria outras possibilidades de interação humana e de presença humana no mundo. Como processo crítico e reflexivo, impulsiona a problematização do que se apresenta como realidade, visa à transformação do que fomenta a desumanização, entretece-se em uma educação que toma os conteúdos como objeto de ad-miração ${ }^{8}$ e se propõe como prática desafiadora.

A pedagogia adquire sentido no âmbito dos diferentes movimentos de participação das classes populares no processo político, com a conscientização do povo sobre a dinâmica de opressão e de subalternização e sobre seu papel como sujeito coletivo na transformação da ordem social dominante. Nesse movimento, a alfabetização das classes populares mostra-se indispensável, como processo em que a leitura do mundo e a da palavra se nutrem mutuamente, afirmando o direito dos sujeitos populares de dizer sua palavra (FREIRE, 2017).

Garcia $(1992,1996,2001)$ converge para esta perspectiva ao tomar como questão central de sua obra a alfabetização das crianças das classes populares. A autora problematiza os muitos desafios cotidianos da escola pública que recebe esses/as estudantes para alfabetizá-los, na acepção freireana do termo. Inconformada com o que se convencionou denominar fracasso escolar, vivido quase que exclusivamente pelos sujeitos subalternizados, a pesquisadora se dedicou fundamentalmente a compreender a ação dos/as estudantes e, concomitantemente, a das professoras alfabetizadoras ${ }^{9}$, no contexto em que a negação do direito à educação de qualidade é permanentemente confrontada pelas conquistas das lutas populares - inclusive fortalecidas na e pela escola. Seu trabalho reafirma os resultados escolares negativos como produção de uma sociedade com altos níveis de concentração de riqueza e de poder, expressão do modo perverso de ver o mundo, característico do pensamento hegemônico. Em diálogo com experiências escolares, convida à reflexão sobre a complexidade da

8 Ad-mirar para Freire é um processo epistemológico. "Ad-mirar o mundo é tomar distância dele para melhor "ler", tanto a origem das relações de opressão como também a capacidade de luta e de resistência que se realiza na esperança de uma sociedade que necessita reinventar-se de baixo para cima para que, entre outras coisas, seja menos difícil amar" (ESCOBAR, 2010, p. 25)

9 A autora utiliza o feminino por ser o magistério constituído predominantemente por mulheres. 
sala de aula, que também se mostra espaçotempo de criação, de aprendizagem, de ensino e de transformação.

A afirmação da dimensão política do fracasso escolar requer uma atuação política no trabalho pedagógico. Os/As professores/as são indispensáveis para que todas as crianças se alfabetizem. O trabalho de formação é igualmente relevante quando nele se desvelam as amarras ideológicas que impedem as ações e se revelam as possibilidades de ruptura com esses obstáculos (GARCIA, 1992).

A reflexão sobre a potência de transformação presente na escola pública evidencia o lugar periférico que as classes populares ocupam na sociedade, na escola e na universidade, tributário do projeto moderno que estrutura a ordem social dominante. A escola mantém as marcas de sua origem como instituição disciplinar articulada aos processos de normalização e classificação hierárquica (FOUCAULT, 2006). Na América Latina, a dimensão de controle da escola se amplifica pelo papel que cumpre na justificativa da dominação colonial, no projeto de subalternização de sua população na composição da própria modernidade ${ }^{10}$ (MIGNOLO, 2003).

Inscrita nessas relações, desde o seu surgimento, a escola pública brasileira tem sua existência atravessada pela afirmação da universalidade, neutralidade e objetividade do conhecimento que só reconhece validade no modo de ser humano e no conjunto de saberes eurocêntricos, cujo resultado é uma dupla negação histórica: dos sujeitos - pensados como o outro que representa o não ser, despossuídos de conhecimentos válidos (DUSSEL, 2006); e dos direitos - interditados às classes populares (GARCIA, 2001). Simultaneamente, a expansão da escola pública e sua democratização respondem às históricas lutas populares pelo direito à escolarização - anunciado, ainda que frequentemente negado. Apoiada nos trabalhos de Freire e Garcia, entendo que para encontrar essa escola que (re) produz possibilidades é preciso olhá-la desde diferentes pontos de vista e buscar as significações várias que podem se enlaçar aos fatos aparentemente uniformes e unívocos, pois a escola de que falamos está tecida pela força da opressão e pela intensidade das lutas pela libertação.

\footnotetext{
10 Para a teoria decolonial, a América Latina é o continente em que um novo padrão de poder mundial se funda, constituindo-se como a primeira periferia do sistema-mundo e como a primeira oportunidade de acumulação primitiva do capital. O conceito de colonialidade apresenta o lado invisível e constituinte da modernidade, que produziu o eurocentrismo como discurso moderno/colonial (MIGNOLO, 2003).
} 
Nesse sentido, podemos compreender as elevadas e persistentes taxas de fracasso escolar como evidência desse movimento, expressando confrontos entre processos de negação da legitimidade dos conhecimentos populares (DUSSEL, 2006), práticas de interdição à aprendizagem (GARCIA, 2001) e insistência dos segmentos sociais postos à margem para permanecerem na escola e transformá-la (FREIRE, 2006). Ainda que altos e inaceitáveis, vínhamos observando uma constante redução dos índices de fracasso escolar, nos últimos anos (IBGE, 2018), indício ao menos da convivência, tecida por muitas tensões, de possibilidades várias no cotidiano escolar. A ação coletiva dos sujeitos também redesenha a escola, seu projeto, suas significações, seus movimentos e seus resultados.

A luta dos movimentos sociais e dos sujeitos subalternizados pela transformação do modelo hegemônico de sociedade é destacada por Garcia (1992), que vê a escola como um dos espaços de tensão e de produção do novo. Com seus estudos, discute como a opressão se traduz nos procedimentos e nas práticas escolares, atuando no sentido de produzir: crianças vistas como incapazes de aprender, famílias distantes da escola, professoras que acreditam existir um único percurso válido de aprendizagem, apoiado em um currículo identificado como único conjunto de conhecimentos válidos. Simultaneamente, a autora apresenta crianças, professoras e famílias que reinventam seu estar com o outro, na escola (GARCIA, 1996). Sua produção evidencia a potência da experiência popular para a problematização da face antidemocrática da escola pública e da própria pedagogia constituída pelo projeto moderno/colonial. Seu pensamento pedagógico compromete-se com as classes populares, com ênfase nos processos de alfabetização e na formação docente, configurados por relações contra-hegemônicas na escola pública.

Essa tecelagem traz desafios ao curso de Pedagogia por demandar sua filiação a um projeto que pretende desarticular a base excludente do projeto dominante de escolarização (GARCIA, 1996). Nesse sentido, coloca a própria docência como objeto de reflexão, necessária para que se realce o vigor que carrega o confronto com a exclusão que a proposição de uma escola para todos ainda enuncia, quando articulada a perspectivas e pesquisas em que predominam análises sobre a escola. Quando a exterioridade demarca essa ação sobre a escola, seus processos, relações e resultados, fomenta processos formativos que pouco interagem com as dinâmicas escolares cotidianas e suas especificidades em 
contextos populares. Evidencia-se ser precário o conhecimento sobre o popular como intensidade (VALLA, 1998).

A formação docente, em seus distintos espaços e tempos, convoca-nos a uma constante reflexão sobre as práticas que a conduzem, considerando: os/ as futuros/as professores/as com quem trabalhamos nos cursos de Pedagogia, aqueles/as que já exercem o magistério e os/as estudantes presentes nas escolas públicas. Nesses movimentos, a potência do diálogo se constitui também pela manifestação de desconhecimentos daqueles/as que se colocam em relação; desconhecimentos resultantes do encontro com as diferenças e desigualdades que se pronunciam e se promovem no cotidiano escolar, como parte das múltiplas experiências que tecem a vida. O diálogo mobiliza a reflexão coletiva e gera movimentos de aprofundamento e ampliação dos conhecimentos de que se dispõe e dos modos de conhecer e pôr em relação os diferentes saberes, o que consolida a compreensão e a atuação críticas para transformar a realidade.

Como destacam Freire e Shor (1986), o diálogo cria e recria, pois o encontro movimenta o pensamento também por trazer o pensamento do outro, que faz repensar: "o diálogo sela o ato de aprender, que nunca é individual, embora tenha uma dimensão individual" (FREIRE; SHOR, 1986, p. 11).

Penso ser esse encontro produzido pelo diálogo um reencontro com os/ as estudantes, alinhavado pelas suas interpelações históricas, mais ou menos silenciosas, que emergem, nesta minha reflexão, na persistência individual e coletiva da criança "que não se alfabetiza" ou a quem "a escola não consegue alfabetizar". Persistência, porque essa criança, cada criança, volta à escola uma e outra vez, muitas vezes durante toda a infância, para tantas vezes retornar posteriormente como adulto, em busca do mesmo: aprender a ler e a escrever. Persistência porque não é uma criança ou outra, um adulto ou outro, mas são gerações de crianças e adultos das classes populares que chegam à escola mais uma vez, a despeito dos fracassos das gerações anteriores e talvez em respeito às lutas que de longe - no tempo e no espaço - vêm sendo travadas pela alfabetização: inicialmente pelo seu direito e atualmente pela efetivação do direito conquistado.

Em cada volta à escola, a cada dia, essas crianças insistentemente apresentadas como incapazes renovam, reafirmam e tornam mais contundente a interrogação das práticas docentes hegemônicas, das concepções de aprendizagem 
naturalizadas nas práticas excludentes e das conformações pouco democráticas de escola ainda vigentes. Portanto evidenciam a insuficiência de um projeto de escola e de educação públicas.

Em cada volta à escola, a cada dia, essas crianças insistentemente apresentadas como incapazes renovam, reafirmam e tornam mais contundente a existência de inúmeros e microscópicos processos e encontros presentes em práticas docentes que dão margem a diálogos e aprendizagens, levam ao questionamento do instituído, proporcionam a percepção de formas múltiplas de aprender, convocam à busca de formas outras de ensinar, articulam práticas que ampliam a potência democrática da escola. Portanto trazem à tona propostas de educação que se alinhavam nas fissuras do projeto de escola insuficiente, evidenciando a potência do projeto de escola pública popular.

A consolidação desse projeto, que se anuncia por aqui e por ali, alimenta a formação docente, a docência cotidiana, as práticas escolares, as ações estudantis, as indagações infantis e as tensões e disputas entre concepções díspares de educação, de escolarização, de alfabetização e de formação. A crescente conquista das classes populares do direito à escolarização ao garantir sua presença massiva na escola pública demanda uma escuta mais atenta as suas questões e maior visibilidade aos seus saberes e processos de aprender e de ensinar. O trabalho educativo se encontra permanentemente com a indagação sobre a favor de quem está.

Esses movimentos impactam intensamente a escola: desestabilizam certezas, formulam questões, fomentam mudanças e nos oferecem meios para vislumbrar e enfrentar os novos desafios que se apresentam constantemente. Igualmente, interpelam a (form)ação docente a se articular a essa dinâmica, fomentando a pronúncia do mundo, portanto, sua problematização e sua transformação, referenciada em um arcabouço ético e político que demanda trabalho coletivo envolvendo curiosidade, compromisso, cooperação, partilha e reflexão crítica. A escola pública popular, nas experiências que se realizam ou que se projetam, só pode ser concebida no diálogo profundo e intenso com as classes populares, que Ihe dão vida e lhe conferem importância. 


\section{OLHAR A ESCOLA COM}

Este é o segundo movimento que proponho neste artigo para pensar a formação docente: olhar a escola com, numa relação dialógica. Movimento significativo para dar continuidade à reflexão sobre a formação docente em seu entrelaçamento com a escola pública e a Educação Popular, ou sobre a formação docente como um dos contextos de composição da escola pública popular.

A formação docente tem fortes vínculos com a universidade, com a qual se relaciona por meio das três atividades que estruturam a vida universitária: ensino, pesquisa e extensão. As modalidades inicial e continuada se articulam às três, enquanto os processos educativos, presentes na escola básica e no ensino superior, são objeto de inúmeras pesquisas. Não se pode, portanto, ignorar no debate o trabalho pedagógico que sustenta a formação.

Cabe indagar os processos formativos e de produção de conhecimento relativos à docência à luz da pedagogia do oprimido. Retomo a compreensão da obra freireana como ruptura com uma pedagogia de caráter tecnicista, voltada à formação do cidadão, em decorrência de seu compromisso com a práxis transformadora na qual a educação das classes populares vislumbra o sujeito coletivo do conhecimento.

A sintonia com os compromissos, demandas e possibilidades que tal ruptura produz requer a problematização das práticas pedagógicas cotidianas a fim de salientar os momentos e contextos em que o trabalho e as relações entre os sujeitos se direcionam por concepções e ações afeitas à educação bancária (FREIRE, 2006). Muito resumidamente, suas principais características podem ser apresentadas como: ênfase na adaptação e no ajustamento dos seres humanos ao mundo e percepção do saber como doação de quem sabe aos que não sabem, fundada na narração e transmissão de conteúdos, visando a sua memorização. Destacam-se a cultura do silêncio, em que negações múltiplas distanciam as classes populares de suas próprias questões, e a prescrição, ato relevante nos processos educativos, traduzido como imposição de uma consciência a outra e crucial à mediação opressor-oprimido. Seu sentido alienador reduz a autonomia dos sujeitos implicados nos processos educativos, incluindo os escolares, e dificulta o pensar autêntico e sua expressão nos atos cotidianos em que se realiza a proposta pedagógica. 
A educação libertadora (FREIRE, 2006) nutre uma concepção de formação docente como processo dialógico, o que ressalta sua dimensão ética e política. Demanda trabalho coletivo, ancorado em ação comprometida, cooperação entre os sujeitos nos espaços intra e extraescolares, partilha de saberes e reflexão crítica, tendo a solidariedade como fio que alinhava esses processos. A reflexão sobre formação e ação docentes, vinculada à educação libertadora, aprofunda-se pelo diálogo com o trabalho de Regina Leite Garcia, tecido pelo forte compromisso com a professora como sujeito político.

Nesse sentido, sobressai sua proposta de formação da professora pesquisadora: "uma professora que pesquisa e uma pesquisadora que ensina" (GARCIA, 1996, p. 21). Concepção, esta, que se inscreve na proposição freireana: "o primeiro pesquisador, na sala de aula, é o professor que investiga seus próprios alunos" (FREIRE; SHOR, 1986, p. 14-5).

Uma compreensão da docência em que ensino e pesquisa se enredam entre si e a processos enraizados na vida cotidiana:

Das salas de aula fomos para as ruas, em busca de melhor compreender como vivem, convivem, sobrevivem as crianças e jovens que vêm fracassando na escola. Fomos também tentar compreender melhor as professoras às quais é dada a responsabilidade de "alfabetizar" [...]. Fomos puxando os fios de suas histórias de vida e, assim fazendo, passamos a olhá-las com olhos mais sensíveis, a tocá-las com um toque mais sensível. Delicadamente, íamos desdobrando pregas que, se antes escondiam tantas histórias, ao serem desdobradas iam revelando uma complexidade até então impensada por nós.

Nossa pesquisa ia se encharcando do cheiro das ruas. [...] Nossa atividade pesquisadora fertilizava nossa atividade docente. (GARCIA, 2001, p. 8)

A formação da professora pesquisadora está em sintonia com o movimento dialógico práticateoriaprática: a prática pedagógica é o ponto de partida e o destino das intervenções, resultantes da pesquisa. Garcia (1992) assume a prática como critério de verdade, em que se dá a confirmação da teoria. Essa abordagem problematiza a formação docente como processo teórico-prático.

A pesquisa torna-se, nessa perspectiva, central na formação e na ação docentes, seja na escola básica, seja na universidade. Decorre da preocupação com a qualidade do ensino e com a identificação dos fundamentos teórico-epistemológicos e políticos de sua prática. Igualmente relevante é a sensibilidade do/a 
professor/a para compreender os percursos de aprendizagem dos/as estudantes, suas questões, seus interesses e suas contribuições para o trabalho escolar, o que incide na elaboração das estratégias de ação docente. A pesquisa se relaciona à produção de um currículo emancipatório, fundado em relações amorosas e compartilhadas. Este não pode prescindir do trabalho com a arte, com a cultura em sua pluralidade, com as diferentes linguagens e formas de expressão, a fim de favorecer a libertação dos corpos e das mentes. Liberdade e criação coletiva se constituem em relações de reciprocidade (GRACIA, 2003b).

A ação pedagógica se propõe a estimular diálogos que qualifiquem a alfabetização como processo de produção, pelas crianças, de significações no mundo em que vivem, nas relações de que participam e sobre si mesmas, acentuando, mais uma vez, a inexistência de prática neutra. A crença na capacidade profissional se revigora nesse exercício formativo em que se conectam reflexão, compreensão e ação, bem como as dimensões prática e teórica da (form)ação docente.

Ao ressaltar a capacidade da professora alfabetizadora de teorizar sobre sua prática, a autora afirma um princípio teórico-epistemológico que sustenta sua posição política de considerar a escola como espaço de teoria em movimento, não se destinando à mera aplicação e reprodução da teoria aprendida. O pedagógico se tece por dinâmicas complexas, reflexivas e dialógicas nas quais os conhecimentos e o ato de conhecer se articulam à busca e produção de explicações para os problemas cotidianamente enfrentados, para os quais não há respostas fáceis, simples ou já dadas. Este ir além se conecta ao reconhecimento da potência da sala de aula como espaço privilegiado para a produção dialógica de conhecimentos.

A professora pesquisadora é aquela que, imersa no cotidiano escolar, aprende a tomar sua experiência docente como objeto de ad-miração (FREIRE, 2006). Inscreve-se criticamente na realidade, amplia sua capacidade de compreensão da micropolítica, mas também dos condicionantes sócio-históricos e culturais que demarcam: a distribuição antidemocrática do poder, as possibilidades desiguais e os reconhecimentos díspares dos modos de ser e dos saberes entretecidos nos modos de ensinar e nas formas de aprender presentes no cotidiano escolar.

A crítica permite a compreensão das situações-limite (FREIRE, 2006) que conformam obstáculos à alfabetização das crianças e dos jovens das classes populares e a sua incorporação como desafios que indicam temas significativos para o 
trabalho em curso. O diálogo e a reflexão geram movimentos que se desdobram na percepção do inédito-viável (FREIRE, 2006), mobilizando a ação transformadora, o aprofundamento de uma educação problematizadora e fortalecendo a esperança. Esse movimento é formativo para a professora pesquisadora, insatisfeita com o fracasso dos/as estudantes e com as justificativas simplificadas que fixam os sujeitos em lugares desqualificados e sem perspectiva.

A educação libertadora traz o encontro como nuclear para a formulação e o desenvolvimento de suas propostas. Nesse sentido, problematiza as relações na sala de aula, no contexto escolar, da escola com a comunidade, e também as que se estabelecem entre a escola e a universidade. Estas historicamente se constituem como uma ação da universidade sobre a escola, o que se relaciona em parte à pesquisa em educação que, ao dizer sobre a escola, por vezes o faz sem dispor de metodologia capaz de tratar da complexidade da vida escolar, valendo-se de um corpo de conhecimento científico que desconhece, em boa medida, as crianças das classes populares (PATTO, 1989).

Sem desconsiderar a relevância de muitas dessas pesquisas e sua importância para a ação docente, a perspectiva indicada pelo pensamento freireano e pela noção de professora pesquisadora, aqui referenciada, alia-se à compreensão dessa limitação. É ainda no trabalho de Garcia que encontro uma proposição de pesquisa em educação que se constitui pelo olhar com, transversal à (form)ação da professora pesquisadora: a pesquisa com o cotidiano (GARCIA, 2003b). Um cotidiano visto em sua complexidade, nunca totalmente apreendido, lugar de atos irrelevantes, em que os problemas da vida existem e exigem solução.

Refiro-me a essa concepção de pesquisa muito brevemente, por meio das palavras de Garcia:

Mergulhar na prática com @s prátic@s, descobrir a riqueza da teoria em movimento que se atualiza no cotidiano, enriquecida pelo que a cada dia se revela como novo. O cotidiano, portanto, como um rico espaço de construção de conhecimentos, as professoras como sujeitos de conhecimentos, assim como as crianças como sujeitos de saberes e a escola como lócus de diferentes saberes que dialogam dialeticamente possibilitando ser cumprida a promessa de uma escola que contribua efetivamente para mudar as vidas de quem nela chega e por ela passa grande parte de sua vida. [...] Portanto, o cotidiano como espaço privilegiado para aprendermos sobre educação em nosso país, pedindo licença para entrar na escola e com ela pesquisar. (GARCIA, 2003b, p. 204-6). 
Sem modelos estruturados e estruturantes e procedimentos predefinidos, a pesquisa com o cotidiano só se faz possível pela relação entre sujeitos e destes com os processos escolares. Essa pesquisa afirma a produção do conhecimento como ato comprometido com a transformação da escola, vista, por sua vez, como espaço de produção de conhecimentos. Mostra-se significativa para o processo de formação, no curso de Pedagogia, que dialoga com a vida escolar e seus desafios.

\section{CONVERSANDO COM AS ESCOLAS, PRODUZINDO CONHECIMENTOS E FORTALECENDO ENCONTROS}

O diálogo entre a escola e a universidade traz para a formação docente questões ligadas ao trabalho na escola pública e à (im)possibilidade de alfabetizar as crianças das classes populares, para circunscrever um dos aspectos centrais deste artigo. Se é certo que tais questões podem ser abordadas desde diversas perspectivas teórico-epistemológicas, nem todas me parecem adequadas para enfrentar o grave fracasso ainda vivenciado em nossas escolas. A Educação Popular, como visto, tem potência para articular transformações que se mostram necessárias.

Trago à conclusão deste texto breves questões presentes na investigação que coordeno ${ }^{11}$, resultantes da realização de uma pesquisa com o cotidiano, pautada na (form)ação da professora pesquisadora. Estar com as professoras ${ }^{12}$ na vida escolar nos possibilita intensificar nossa reflexão sobre a (form)ação promovida na universidade e a produção de vínculos entre a escolarização e a Educação Popular.

Tendo como fio condutor um estudo sobre o impacto dos resultados da Provinha Brasil nos processos de alfabetização, considerando os modos de compreensão da infância na escola e as propostas de integração das crianças à dinâmica escolar, vamos às escolas para compreender, com as professoras, o encaminhamento do trabalho pedagógico em suas salas de aula. Nesse diálogo, a partir do que emergia em suas experiências cotidianas, notadamente o relativo às articulações entre a avaliação dos/as estudantes e o trabalho proposto, obser-

\footnotetext{
11 - Conforme indicado anteriormente, coordeno um grupo composto por cinco pesquisadoras e um pesquisador. Uso a 1a pessoa do plural toda vez que me refiro ao que resulta desse coletivo.

$12 \mathrm{Na}$ pesquisa aqui referida, trabalhou-se exclusivamente com mulheres.
} 
vamos em suas afirmações sobre as crianças e seus resultados, sobre os sentidos das atividades propostas, sobre os limites impostos à sua ação profissional e em seus questionamentos e problematizações o quanto assumir a perspectiva da Educação Popular coloca em jogo os significados - do ensinar, do aprender, do conhecimento, do lugar e da função da docência - fortemente enraizados no projeto iluminista. Delineia-se a possibilidade de interpelar a oposição aos saberes populares e a pretensão de ensinar o mesmo a todos como expressão da face democrática da escola. A fluidez do que expressam as palavras exige, em nosso caso, a observação de que a significação de prática dialógica, reflexiva e democrática se produz diante do compromisso com as classes populares.

A escola da padronização e busca da homogeneidade mantém altos índices de estudantes que chegam ao 3 o ano do ensino fundamental com uma capacidade de leitura e de escrita bastante reduzida, evidência da alfabetização das crianças das classes populares como uma situação-limite, no cotidiano escolar. Para enfrentá-la, são necessárias propostas que mobilizem as aprendizagens infantis e qualifiquem a (form)ação docente. Na pesquisa assumimos coletivamente as questões formuladas com as professoras e com as crianças, objetos de trabalho em cada contexto em que se apresentam e no grupo de pesquisa. Passam também a constituir e problematizar o conteúdo das disciplinas que leciono e das atividades de extensão que organizo na universidade.

Esse movimento, significativo para a (form)ação docente, resulta em temas de estudo. A seguir, abordo dois deles: referente à condução da pesquisa e ao conhecimento presente na prática pedagógica.

A interação entre escola básica e universidade e entre professoras e professores, atuando em diferentes níveis de ensino, expõe a complexidade da produção de dados na pesquisa com o cotidiano escolar. Ressaltamos sua dimensão ética, pois não estamos tratando com objetos de pesquisa, mas com produções, atos, discursos de sujeitos, que falam de quem os produziu e são reconhecidos pelos seus/suas autores/as. Portanto o anonimato não resolve a questão ética que se coloca: o que de si cada um/a quer dar a ver, como quer se reconhecer nos momentos de exposição da pesquisa. Este tem sido um tema recorrente em nossos trabalhos, ganhando destaque naqueles em que nossa proposta envolve a presença das crianças. A pesquisa com o cotidiano nos convida a partilhar encaminhamentos e decisões, tornando patente a necessidade de distinção entre 
os resultados que são de interesse exclusivo dos grupos e sujeitos envolvidos na investigação e o que pode e deve ser apresentado publicamente como seu produto. A negociação mostra-se central ao trabalho, permite-nos experimentar alternativas que fortalecem o diálogo entre pesquisa, formação e práticas pedagógicas e mantém a vitalidade de muitas perguntas.

Ainda que nem todas as respostas tenham sido dadas, podemos olhar a escola com, conversar, experimentar parcerias na reflexão, enfim, viver a pesquisa e a formação como processos coletivos que se fortalecem mutuamente. Este debate, mesmo inconcluso, reafirma a potência da formação da professora pesquisadora e dos princípios da Educação Popular.

Outra questão relevante é o frequente desencontro entre as propostas de ensino da professora e os processos de aprendizagem das crianças, o qual tem nos permitido muitos desdobramentos nas distintas esferas de nossa ação e nos leva à problematização tanto de práticas quanto de teorias. Vale notar que tal desencontro só pode ser observado pela presença das crianças na pesquisa, que tomam a palavra e se inscrevem em movimentos que exigem o exercício da escuta atenta, sem a qual não há diálogo. O diálogo, ou sua ausência, dá visibilidade ao lugar da diferença no processo de alfabetização, ao lugar que a própria criança e seus saberes ocupam na dinâmica pedagógica e a indagações sobre as interfaces da ação dialógica com a alfabetização infantil.

Como expressão desse desencontro está a primazia, nos contextos estudados, de um processo pedagógico marcado por atividades nas quais predomina a perspectiva mecanicista de alfabetização, dando-se prioridade ao desenvolvimento de habilidades e competências necessárias à codificação e decodificação do texto, considerado uma produção objetiva e linear, desarticulada de quem escreve e lê. Esta concepção é convergente para a ótica da avaliação externa efetivada por meio de testes estandardizados, cujas questões se concentram nas dimensões mais superficiais da alfabetização, possíveis de serem observadas em respostas de múltipla escolha (ESTEBAN, 2009). Essa prática, embora predominante, não se mostrou exclusiva: todas as professoras envolvidas na pesquisa indicaram a fragilidade desse processo e a força da avaliação externa na conformação de suas propostas; algumas nos mostraram suas buscas por outros caminhos e a única escola que não se submete aos exames externos (dentre as que se envolveram com a pesquisa) apresentou um movimento de crítica a essa perspectiva domi- 
nante que levou a incluir a alfabetização como processo discursivo no conjunto de temas a serem tratados na formação continuada que realiza. O desencontro promove a problematização.

Embora as classes populares predominem na escola pública brasileira, veio à tona, na pesquisa, a frequente invisibilidade do popular, ou sua compreensão como carência (VALLA, 1998), na formulação do trabalho pedagógico. Vivendo a escola com as professoras e crianças, nos encontramos com processos de alfabetização com pouca proximidade com a ideia de alfabetização como ato político, de conhecimento e criador (FREIRE, 2017, p. 9), nexo limitado da dinâmica escolar com a cultura popular e frágil relação com processos dialógicos e reflexivos. Contudo, em todos os casos, o convite ao trabalho coletivo, solidário e colaborativo foi aceito pelas professoras e pelas crianças e gerou mudanças, com intensidades variadas, nos diversos cotidianos estudados. O encontro é potente para fortalecer o projeto de escola pública popular.

Os exercícios de pensar a escola pública com muitos sujeitos e perspectivas a partir da (form)ação docente nos dão pistas significativas sobre como promover articulações que resultem em parcerias que indaguem o projeto de educação vigente, inclusive na universidade. A produção de relações dialógicas tem resultado na tecelagem de redes de preocupações, conhecimentos, questões, aprendizagens, significações e desafios que se entretecem nos diferentes contextos, com diferentes sujeitos, sem, contudo, se desfazerem totalmente de amarras que traduzem a subalternização que historicamente demarca limites (sempre tensionados) para o ser, o saber e o poder das classes populares. O compromisso com a transformação ganha densidade na medida em que situações naturalizadas passam a ser problematizadas e se tornam material sobre o qual refletir coletivamente. Estas se configuram em alternativas de ação que evidenciam a solidariedade e a ampliação do conhecimento, e a partilha dos diferentes saberes que se enredam no cotidiano ganha sentido mais profundo. A amorosidade se apresenta nos processos vividos que revelam mudanças, sem escamotear permanências nem sempre desejadas.

O diálogo, os encontros, as ligeiras conversas cotidianas e as tantas formas de estar com são indispensáveis aos movimentos de transformação das práticas escolares, dos processos alfabetizadores e dos percursos de formação docente para romper com a cultura do silêncio e com a prescrição, que encaminham uma 
escolarização fundada na lógica da exclusão, sustentação do projeto hegemônico de educação. Mesmo nos contextos desfavoráveis aos movimentos de libertação, em que retrocedem as frágeis conquistas democráticas, é preciso fortalecer o lugar das práticas pedagógicas na luta contra as opressões. Como sabem as professoras que trabalham com as classes populares, não há tempo para desânimo. A Educação Popular nos convoca a manter acesa a chama da esperança.

\section{REFERÊNCIAS}

AFONSO, Almerindo J. Escola pública, comunidade e avaliação. Resgatando a avaliação formativa como instrumento de emancipação. In: ESTEBAN, Maria Teresa (Org.). Avaliação: uma prática em busca de novos sentidos. Rio de Janeiro: DP\&A,1999. p. 83-99.

ARROYO, Miguel G. Políticas educacionais, igualdade e diferenças. Revista Brasileira de Política e Administração da Educação, v. 27, n.1, p. 83-94, jan./abr. 2011.

BECKER, Fernando. Epistemologia. In: STRECK, Danilo; REDIN, Euclides; ZITKOSKI, Jaime (Org.). Dicionário Paulo Freire. Belo Horizonte: Autêntica, 2010. p. 152-4.

BRZEZINSKI, Iria. Formação de profissionais da educação (2003-2010). Brasília: INEP, 2014.

DUSSEL, Enrique. Ética de la liberación en la edad de la gobalización y de la exclusión. 5. ed. Madrid: Trotta, 2006.

ESCOBAR, Miguel. Ad-mirar. In: STRECK, Danilo; REDIN, Euclides; ZITKOSKI, Jaime (Org.). Dicionário Paulo Freire. Belo Horizonte: Autêntica, 2010. p. 24-6.

ESTEBAN, Maria Teresa. Provinha Brasil: desempenho escolar e discursos normativos sobre a infância. Sísifo: Revista de Ciências da Educação, Lisboa, n. 09, p. 47-56, maio/ago. 2009.

ESTEBAN, Maria Teresa; ECKHARDT, Fabiana. Subalternidade e libertação: questões e perspectivas para a formação docente. In: TAVARES, José; CUNHA, Maria Isabel da; SHIGUNOV NETO, Alexandre; FORTUNATO, Ivan (Org.). Docência no ensino superior: experiências no Brasil, Portugal e Espanha. São Paulo: Edições Hipótese, 2019. p. 289-308.

FOUCAULT, Michel. É preciso defender a sociedade. Porto, Portugal: Livros do Brasil, 2006.

FREIRE, Paulo. A importância o ato de ler. 51. ed. São Paulo: Cortez, 2017.

FREIRE, Paulo. Pedagogia do oprimido. 43. ed. Rio de Janeiro: Paz e Terra, 2006. 
FREIRE, Paulo; SHOR, Ira. Medo e ousadia. O cotidiano do professor. Rio de Janeiro: Paz e Terra, 1986.

GARCIA, Regina L. (Org.). Método: pesquisa com o cotidiano. São Paulo: Cortez, 2003a.

GARCIA, Regina L. A difícil arte/ciência de pesquisar com o cotidiano. In: GARCIA, Regina L. (Org.). Método, métodos, contramétodo. São Paulo: Cortez, 2003b. p. 193-208.

GARCIA, Regina L. (Org.). Novos olhares sobre alfabetização. São Paulo: Cortez, 2001.

GARCIA, Regina L. (Org.). Formação de professoras alfabetizadoras - reflexões sobre a prática. São Paulo: Cortez, 1996.

GARCIA, Regina L. (Org.). Alfabetização dos alunos das classes populares. São Paulo: Cortez, 1992.

IBGE. Pesquisa Nacional por Amostra de Domicílios Contínua 2016-2018. Rio de Janeiro: IBGE, 2018.

MIGNOLO, Walter. Histórias locais/Projetos globais - colonialidade, saberes subalternos e pensamento liminar. Belo Horizonte: UFMG, 2003.

PATTO, Maria Helena de Souza. A produção do Fracasso escolar - histórias de submissão e rebeldia. São Paulo: T.A.Queiroz, 1989.

PEREIRA, Thiago I. Epistemologia freireana e pós-colonialidade - reflexões a partir da pesquisa participante na América Latina. Revista de Estudos AntiUtilitaristas e PosColoniais, Recife, v. 4, n. 02, p. 33-48, jul./dez. 2014.

ROMANOWSKI, Joana P. Apontamentos em pesquisas sobre formação de professores: contribuições para o debate. Revista Diálogo Educacional, Curitiba, v. 12, n. 37, p. 90524, set./dez. 2012.

STRECK, Danilo (Org.). Fontes da pedagogia latino-americana - uma antologia. Belo Horizonte: Autêntica, 2010.

TORRES, Alfonso. A Educação Popular como prática política e pedagógica emancipadora. In: STRECK, Danilo; ESTEBAN, Maria Teresa (Org.). Educação Popular - lugar de construção social coletiva. Petrópolis, RJ: Vozes, 2013. p. 15-32.

VALLA, Victor V. Sobre participação popular: uma questão de perspectiva. Cadernos de Saúde Pública, Rio de Janeiro, v. 14, supl. 2, p. 7-18, 1998. 


\section{Sobre a autora:}

Maria Teresa Esteban: Doutora em Filosofia e Ciências da Educação pela Universidade de Santiago de Compostela, com Pós-Doutorado na UNAM e na Universidade do Minho. Professora da Faculdade de Educação da Universidade Federal Fluminense (UFF), atuando na Graduação em Pedagogia e no Mestrado e Doutorado em Educação. E-mail: mtesteban@uol.com.br, Orcid: http://orcid.org/0000-0003-0130-149X

Recebido em 22 de setembro de 2019

Aprovado em 5 de novembro de 2019 